\title{
ATP-Binding Cassette Transporter ABC2/ABCA2 in the Rat Brain: A Novel Mammalian Lysosome-Associated Membrane Protein and a Specific Marker for Oligodendrocytes But Not for Myelin Sheaths
}

\author{
Cheng-Ji Zhou,, ${ }^{1,4}$ Li-Xia Zhao, ${ }^{2}$ Nobuya Inagaki, ${ }^{2,5}$ Jian-Lian Guan, ${ }^{1}$ Shigeo Nakajo,, ${ }^{3}$ Takahiro Hirabayashi, ${ }^{3}$ \\ Sakae Kikuyama, ${ }^{4}$ and Seiji Shioda ${ }^{1,5}$ \\ ${ }^{1}$ Department of Anatomy, Showa University School of Medicine, Tokyo, 142-8555 Japan, 2Department of Physiology, \\ Akita University School of Medicine, Akita, 010-8543 Japan, ${ }^{2}$ Laboratory of Biological Chemistry, Showa University \\ School of Pharmaceutical Sciences, Tokyo, 142-8555 Japan, ${ }^{4}$ Department of Biology, Waseda University School of \\ Education, Tokyo, 168-8050 Japan, and 5 Department of Anatomy I, Showa University School of Medicine, Core \\ Research for Evolutional Science and Technology, Japan Science and Technology Corporation, 1-5-8 Hatanodai, \\ Shinagawa-ku, Tokyo 142-8555 Japan
}

\begin{abstract}
We recently cloned a full-length cDNA of the rat ATP-binding cassette transporter 2 ( $A B C 2$, or $A B C A 2)$ protein, a member of the $A B C 1$ (or $A B C A)$ subfamily (-ABC1/ABCA1 is a causal gene for Tangier disease) and found it to be strongly expressed in the rat brain. In this study, we identified $A B C 2$ as a lysosomeassociated membrane protein that is being localized specifically in oligodendrocytes. The ABC2-immunolabeled cells were detected mainly in the white matter but were also scattered in gray matter throughout the whole brain. In addition, these cells were found to be colocalized with 2 ', 3 '-cyclic nucleotide-3'phosphodiesterase (CNPase) immunoreactivity when the marker antibody for oligodendrocytes was used. However, no such colocalization was observed with markers for other kinds of glial cells. Unlike the CNP antibody, which also intensely stains myelin sheaths in the white matter, ABC2 immunoreactivity was detected only in the cell bodies of oligodendrocytes. At the ultrastructural level, $\mathrm{ABC} 2$ immunoreactivity was de-
\end{abstract}

tected mostly around lysosome and partly in Golgi apparatus by electron microscopy. This was confirmed by immunocolocalization of $\mathrm{ABC} 2$ and lysosomal markers in a neuroblastoma cell line. Immunoblotting analysis of $A B C 2$ from the whole brain and the ABC2-transfected cell line revealed bands at $\sim 260$ $\mathrm{kDa}$. The result of in situ hybridization with a riboprobe for $\mathrm{ABC} 2$ matched the results obtained from immunostaining. These findings strongly suggest that $A B C 2$ is a specific marker for oligodendrocytes but not for myelinsheaths and that it is as a novel mammalian lysosome-associated membrane protein involved in myelinization or other kinds of metabolism in the CNS.

Key words: ATP-binding cassette $(A B C)$ transporter; $A B C 1$ (or ABCA) subfamily; ABC2/ABCA2; oligodendrocytes; myelinization; lysosomes; marker protein; CNPase; lysosomeassociated membrane protein LAMP1/LAMP2; rat brain
To date, hundreds of evolutionarily conserved membrane proteins have been identified as members of the ATP-binding cassette (ABC) transporter (or traffic ATPase) superfamily. These proteins have been implicated in the energy-dependent transport of a wide variety of substrates across the organellar or plasma membranes of both prokaryotic and eukaryotic cells (Higgins, 1992; Doige and Ames, 1993; Allikmets et al., 1996; Linton and Higgins, 1998; Saurin et al., 1999). Typical eukaryotic ABC transporters (full-molecule) consist of two transmembrane domains and two ATP-binding cassettes. Half-molecule transporters have only a single transmembrane domain and ATP-binding cassette, whereas quarter-molecule transporters have only an

\footnotetext{
Received June 26, 2000; revised Oct. 31, 2000; accepted Nov. 10, 2000.

This research was supported in part by grants from the Ministry of Education, Science, Sports, and Culture of Japan (S.S., S.K., and N.I.) and Core Research for Evolutional Science and Technology of Japan Science and Technology Corporation (N.I. and S.S.), as well as by a grant to C.J.Z. from the Foundation for Growth Science (Tokyo, Japan). We thank Dr. Masanori Nakata (Jichi Medical School, Department of Physiology, Tochigi, Japan) for providing the neuro-2a cell line, and Sachiko H. Kajimoto and Mio Watanabe (Showa University School of Pharmaceutical Sciences) for their assistance with this study.

Correspondence should be addressed to Dr. Seiji Shioda, Department of Anatomy, Showa University School of Medicine, Tokyo 142-8555, Japan. E-mail: shioda@ med.showa-u.ac.jp.

Copyright (C) 2001 Society for Neuroscience $\quad 0270-6474 / 01 / 210849-\bullet \$ 15.00 / 0$
}

ATP-binding cassette (Hyde et al., 1990; Dean and Allikmets, 1995; Decottignies and Goffeau, 1997).

Many mammalian ABC transporters have recently been found to be associated with clinically relevant phenotypes, including neurodegenerations. X-linked adrenoleukodystrophy (ALD), which results in a fatal demyelinating disease, has been linked to mutations in a $70 \mathrm{kDa}$ peroxisomal ABC transporter (Kamijo et al., 1990; Mosser et al., 1993; Dubois-Dalcq et al., 1999), and an autosomal recessive retinal disorder, Stargardt's macular dystrophy, has been connected to a retina-specific ABC transporter (ABCR/ABCA4) gene (Allikmets et al., 1997; Illing et al., 1997; Weng et al., 1999). Other genetic diseases reported to be linked to mutations of ABC transporters include cystic fibrosis (Sheppard and Welsh, 1999), persistent hyperinsulinemic hypoglycemia of infancy (Thomas et al., 1995), congenital jaundice (Paulusma et al., 1996), intrahepatic cholestasis (Strautnieks et al., 1998), and pseudoxanthoma elasticum (Ringpfeil et al., 2000).

We have cloned and characterized a full-length rat ATPbinding cassette transporter cDNA for ABC2/ABCA2, which encodes for a glycoprotein of 2434 amino acids with 44.5, 40.0, and $40.8 \%$ identity with mouse ABC1/ABCA1, human ABC3/ $\mathrm{ABCA} 3$, and human $\mathrm{ABCR} / \mathrm{ABCA} 4$, respectively (Zhao et al., 2000). ABC2 belongs to the ABC1 (ABCA) subfamily, which is 
structurally distinct from other subfamilies. Four members of this subfamily have been identified and named ABC1 (Luciani et al., 1994), ABC2 (Luciani et al., 1994; Zhao et al., 2000), ABC3 (ABC-C) (Klugbauer and Hofmann, 1996), and ABCR (Illing et al., 1997). This subfamily has recently received much attention because it has been proposed that $\mathrm{ABC} 1$ and $\mathrm{ABCR}$ are flippases (Higgins, 1994; Weng et al., 1999), and they have also been identified as the causal genes for Tangier disease (Bodzioch et al., 1999; Brooks-Wilson et al., 1999; Rust et al., 1999; Orso et al., 2000) and Stargardt's macular dystrophy.

Although it has been reported that $\mathrm{ABC} 2$ is expressed abundantly in rat and mouse brains (Luciani et al., 1994; Zhao et al., 2000) and it has been hypothesized that ABC2 may play a very important role in the mammalian CNS, knowledge of the morphology and physiological functions of this protein remains poor. The present study aims to identify the ABC2-expressing cell types in the brain and to determine its ultrastructural localization.

\section{MATERIALS AND METHODS}

\section{Animals}

Two or four male adult rats (2- or 3-month-old Sprague Dawley; Saitama Experimental Animal Center, Saitama, Japan) were used for each experiment. Rats were housed in a temperature- and light-controlled room $\left(22^{\circ} \mathrm{C}\right.$, lights on at 6:00 A.M. and off at 8:00 P.M.) and fed standard Oriental Chow and water ad libitum. Two to five animals were used in each experiment. During the experiments, all efforts were made to minimize suffering of the animals, in accordance with the National Institutes of Health Guidelines for the Care and Use of Laboratory Animals.

\section{Primary antibodies}

The specific antibody for $\mathrm{ABC} 2$ was raised in rabbits against the synthetic peptide corresponding to $20 \mathrm{C}$-terminal amino acid residues (GLISFEEERAQLSFNTDTLC) of rat ABC2, which constructively differs from the other members of the $\mathrm{ABC} 1$ subfamily or any other protein from the sequence databases. The antibody was purified using affinity chromatography (HiTrap Protein G, Amersham Pharmacia Biotech). To identify the $\mathrm{ABC} 2$-expressing cell types in this study, double immunofluorescence was performed using the monoclonal mouse anti-human $2^{\prime}, 3^{\prime}$-cyclic nucleotide-3' -phosphodiesterase (CNPase; Sigma C5922) as a marker for oligodendrocytes (Sprinkle et al., 1987) and the monoclonal mouse anti-rat CD11b (Serotec, Kidlington, Oxford, England) as a marker for microglial cells in the brain (Milligan et al., 1991). In addition, the rabbit anti-myelin basic protein (MBP) (Dako, Carpinteria, CA) and the rabbit anti-glial fibrillary acidic protein (GFAP; Sigma G9269), a marker for astrocytes, were also used. Furthermore, two affinity-purified goat polyclonal antibodies against human lysosome-associated membrane proteins LAMP1 (N-19; Santa Cruz Biotechnology, Santa Cruz, CA) and LAMP2 (C-20; Santa Cruz Biotechnology) were used to identify the lysosomal colocalization (Karlsson and Carlsson, 1998).

\section{Western blot analysis}

Cell culture and transfection. To demonstrate the specificity of the antibody for $\mathrm{ABC} 2$ used in the present study, the rat $\mathrm{ABC} 2$ expression vector (pCMVrABC2) was transfected into cultured COS-1 cells. Culture and transfection of COS-1 cells was performed as previously described (Zhao et al., 2000). Briefly, cells were plated on $35 \mathrm{~mm}$ culture dishes at a density of $2 \times 10^{5}$ cells per dish $24 \mathrm{hr}$ before transfection and cultured in DMEM (450 mg/dl glucose) supplemented with $10 \%$ fetal calf serum. Two micrograms of pCMVrABC2 were transfected into cells with Lipofectamine and Opti-MEM I (Life Technologies), according to the manufacturer's instructions.

Crude membrane preparation. Crude membrane from COS- 1 cells was prepared as described previously (Zhao et al., 2000). Briefly, for immunoblot analysis, $3 \mathrm{~d}$ after transfection with $\mathrm{pCMVrABC2}$ or pCMV vector alone, the COS-1 cells were washed three times with PBS, suspended in buffer A consisting of $50 \mathrm{~mm}$ Tris, $\mathrm{pH} 7.5$, and $1 \mathrm{~mm}$ EDTA containing protease inhibitor mixture $(10 \mu \mathrm{l} / \mathrm{ml})$ (Sigma), homogenized, and then centrifuged at $100,000 \times g$ for $1 \mathrm{hr}$ at $4^{\circ} \mathrm{C}$. The pellets were resuspended in $500 \mu \mathrm{l}$ of buffer $\mathrm{A}$ and stored at $-80^{\circ} \mathrm{C}$ until used. Protein concentrations were determined using the BCA assay (Pierce, Rockford,
IL). For preparation of crude membrane from the rat brain, the whole brain were immediately dissected into buffer A containing protease inhibitor mixture $(10 \mu \mathrm{l} / \mathrm{ml})$ (Sigma), and the tissue suspension was homogenized in a Teflon pestle-glass homogenizer on ice and centrifuged at $800 \times g$ for $7 \mathrm{~min}$ at $4^{\circ} \mathrm{C}$. The supernatant was subjected to ultracentrifugation at $100,000 \times g$ for $1 \mathrm{hr}$ at $4^{\circ} \mathrm{C}$, and the collected pellets were resuspended in $500 \mu \mathrm{l}$ of buffer $\mathrm{A}$ and stored at $-80^{\circ} \mathrm{C}$ until immunoblot analysis.

Immunoblot analysis. The crude membrane proteins from brain tissue $(60 \mu \mathrm{g})$ or from the COS-1 cells $(3 \mu \mathrm{g})$ were boiled in SDS reducing sample buffer for $10 \mathrm{~min}$ and electrophoresed on a $7 \%$ SDSpolyacrylamide gel, then transferred electrophoretically to a nitrocellulose membrane (Hybond ECL, Amersham Pharmacia Biotech) at $4^{\circ} \mathrm{C}$ at $200 \mathrm{~mA}$ overnight. The membrane was blocked in 5\% defatted milk in $0.1 \%$ Tween 20-PBS (PBS-T) for $1 \mathrm{hr}$ at room temperature. After washing with PBS-T, the membrane was incubated with 1:500 diluted $\mathrm{ABC} 2$ antibody for $2 \mathrm{hr}$ at room temperature and washed with PBS-T. The membrane was then incubated with 1:5000 diluted horseradish peroxidase-conjugated anti-rabbit IgG (Amersham Pharmacia Biotech) for $1 \mathrm{hr}$ at room temperature. After washing with $0.3 \%$ Tween 20-PBS and then with PBS-T, protein bands were detected using an enhanced chemiluminescence system (ECL, Amersham Pharmacia Biotech), according to the manufacturer's instructions.

\section{Immunohistochemistry}

Tissue preparation. The animals were deeply anesthetized with pentobarbital $(50 \mathrm{mg} / \mathrm{kg}$, i.p.) and perfusion-fixed with $4 \%$ paraformaldehyde and $0.1 \%$ glutaraldehyde buffer, $\mathrm{pH}$ 7.4. Then the brains were removed quickly and post-fixed in $4 \%$ paraformaldehyde for $2 \mathrm{hr}$ or more. After the brains were permeated with $20 \%$ sucrose for 1 or $2 \mathrm{~d}$, they were frozen in an embedding compound (Sakura Finetechnical, Tokyo, Japan) on isopentane using liquid nitrogen and stored at $-70^{\circ} \mathrm{C}$ until used. Frozen $7-\mu \mathrm{m}$-thick coronal or sagittal sections were cut with a cryostat (Microm HM500, Heidelberg, Germany) and thaw-mounted on poly-Llysine-coated glass slides.

Immunofluorescence. This procedure was performed as described previously (Zhou et al., 1999), although with some modification in relation to double labeling. The brain sections were blocked in $10 \%$ normal goat serum (NGS) and 1\% bovine serum albumin, as well as $0.3 \%$ Triton $\mathrm{X}-100$, in $0.1 \mathrm{M}$ PBS for $1 \mathrm{hr}$ at room temperature. Except for the MBP antibody that was used directly, each primary antiserum was diluted 1:500 in PBS containing 1\% NGS or diluted together for double staining and was incubated overnight at $4^{\circ} \mathrm{C}$. The antisera were then rinsed and incubated with one or two secondary antibodies for $1 \mathrm{hr}$ at room temperature. For $\mathrm{ABC} 2 / \mathrm{CNP}$ double labeling, Alexa 546-conjugated goat anti-rabbit IgG (for $\mathrm{ABC} 2$ ) and Alexa 488-conjugated goat anti-mouse IgG (for CNPase) were diluted 1:200 in PBS. In the case of ABC2/ CD11b double labeling, Alexa 488-conjugated goat anti-rabbit IgG (for $\mathrm{ABC} 2$ ) and Alexa 546-conjugated goat anti-mouse IgG (for CNPase) were used. For MBP or GFAP single staining, Alexa 546-conjugated goat anti-rabbit $\operatorname{IgG}$ was used as the second antibody. After washing in PBS, the sections were counterstained with Hoechst $33258(1 \mu \mathrm{g} / \mathrm{ml}$, Sigma) for $1 \mathrm{~min}$ and rinsed. In the case of ABC2/LAMP1 double staining, Alexa 546-conjugated donkey anti-goat IgG (for LAMP1) was used first, and then Alexa 488-conjugated goat anti-rabbit IgG (for ABC2) was used. For ABC2/LAMP2, Alexa 488-conjugated donkey anti-goat IgG (for LAMP2) was used first, and then Alexa 546-conjugated goat antirabbit $\operatorname{IgG}$ (for $\mathrm{ABC}$ ) was used. The slides were then coverslipped with PermaFluor Aqueous mounting medium (Immunon, Pittsburgh, PA).

Fluoromicroscopy and confocal microscopy. Fluorescence immunolabeling was detected using a U-MNIBA filter cube (Olympus, Tokyo, Japan) for Alexa 488, a U-MWIG filter cube for Alexa 546, and a U-MNU filter cube for Hoechst 33258. A U-MDA/FI/TR cube was used for triple-fluorescence immunolabeling with a fluoromicroscope (AX-70, Olympus). In the case of ABC2/LAMP1 or LAMP2 double staining, the confocal microscope (Leica TCS SP2, Leica, Microsystems, Heidelberg, Germany) was used.

\section{Immunoelectron microscopy}

Free-floating immunolabeling. Vibratome sections $(30 \mu \mathrm{m})$ from the perfusion-fixed brain tissue were used to perform a preembedding immunoperoxidase method. After blocking and permeation as described above, the sections were floated in the primary antibody buffer (rabbit anti-ABC2, 1:1000) on ice overnight. A biotinylated anti-rabbit IgG (Vector Labs, Burlingame, CA) (diluted 1:400) was used as the secondary 


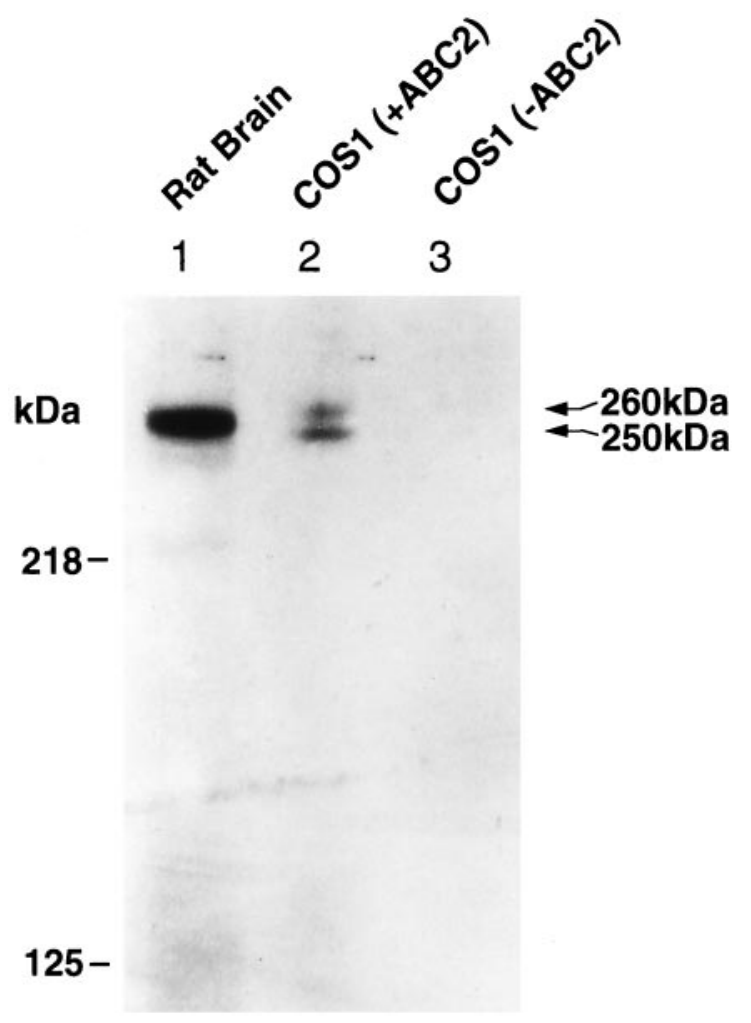

Figure 1. Immunoblot analysis of $\mathrm{ABC} 2$ protein. Membrane proteins from rat whole brain $(60 \mu \mathrm{g})$ (lane 1) and COS-1 cells transfected with $\mathrm{ABC} 2$ expression vector $(3 \mu \mathrm{g})(\mathrm{pCMVrABC} 2)$ (lane 2) and $\mathrm{pCMV}$ vector alone $(3 \mu \mathrm{g})$ (lane 3$)$ were electrophoresed on a $7 \%$ SDSpolyacrylamide gel. For immunoblot analysis, 1:500 diluted anti-ABC2 rabbit antibody and 1:5000 diluted horseradish peroxidase-conjugated anti-rabbit $\operatorname{IgG}$ were used as the primary and secondary antibodies, respectively. Proteins were detected using an enhanced chemiluminescence system. Molecular weights of markers are indicated on the left, and the detected 260 and $250 \mathrm{kDa}$ bands are indicated by arrows.

antibody, with a $1 \mathrm{hr}$ incubation at room temperature. The sections were then labeled with avidin - biotin-peroxidase complex (ABC Kit, Vector) and color-developed with a 3,3'-diaminobenzidine tetrahydrochloride (DAB)-substrate kit (Vector) for light-microscope or direct electron microscope observation.

Silver-gold intensification. To obtain clearer electron micrographs (or for double staining to detect a secondary antigen), the peroxidase-DAB reaction product was intensified as described previously (Guan et al., 2000). Briefly, the sections (after DAB reaction) were treated with $10 \%$ thioglycolic acid for $2 \mathrm{hr}$ at room temperature to inhibit nonspecific binding of silver in tissue compartments and rinsed with $2 \%$ sodium acetate. Then the sections were transferred to a physical developer (Gallyas et al., 1982) (mixture of $0.2 \mathrm{ml} 37 \%$ formalin, $50 \mathrm{ml}$ solution containing $0.2 \%$ ammonium nitrate, $0.2 \%$ silver nitrate, $1 \%$ silicotungstic acid, and $50 \mathrm{ml} \mathrm{5 \%}$ sodium carbonate) for 3-10 min for silver intensification, after which the reaction was stopped with $1 \%$ acetic acid, and the sections were rinsed with $2 \%$ sodium acetate. Finally, the sections were transferred into a $0.05 \%$ gold chloride solution for $10 \mathrm{~min}$ to enhance the stability of the metallic particles and the electron density, then rinsed and recovered in $0.1 \mathrm{M}$ PBS, $\mathrm{pH} 7.4$, for use in the next step.

Electron microscopy. The sections were post-fixed with $1 \%$ osmium tetroxide (in 0.1 m PBS), dehydrated with a graded series of ethanol, and flat-embedded in Epon-Araldite mixture. Ultrathin sections were cut with a Reichert Ultracut Microtome, from the corpus callosum, anterior commissure, optic chiasm, and the medulla of cerebellum, and observed using a Hitachi H7000 electron microscope without counterstaining. The morphological identification for oligodendrocytes and other glial cells as well as the organellar structures were consulted in Peters et al. (1976).

In situ hybridization. The first half of this experiment was performed as described previously (Zhao et al., 2000). The fresh-frozen brain sections and a $\left[{ }^{35} \mathrm{~S}\right]$-labeled 400 bp $\mathrm{ABC} 2$ riboprobe were used.
Slide emulsion and signal development. As a continuous procedure (Shioda et al., 1997), the slides of hybridized brain sections (after exposure to $\mathrm{x}$-ray film) were dipped in a nuclear track emulsion (NTB2; Kodak, Rochester, NY) at $42^{\circ} \mathrm{C}$, air-dried, and then left in the dark to expose for 1 week. They were then developed in a Kodak D19 developer $\left(20^{\circ} \mathrm{C}, 2 \mathrm{~min}\right)$, fixed in Kodak Rapid Fixer, counterstained with hematoxylin and eosin, and then analyzed under dark- and bright-field microscopy.

\section{RESULTS}

\section{Immunoblot analysis of rat brain and ABC2-transfected cells}

Immunoblot analysis for both brain tissue and the transfected cell samples was performed using the specific antibody for ABC2. A single band between molecular weight 260 and $250 \mathrm{kDa}$ was detected from the total membrane fraction of the rat whole brain (Fig. 1, lane 1), and two bands of 260 and $250 \mathrm{kDa}$ were detected from the total membrane fraction of COS-1 cells transfected with $\mathrm{ABC} 2$ expression vector (pCMVrABC2) (Fig. 1, lane 2). However, no band was detected from those transfected with pCMV vector only (Fig. 1, lane 3).

\section{Cellular identification of $\mathrm{ABC2}$ in the cerebellum and the anterior commissure}

In the cerebellum of rats considered in this study, intense ABC2 immunoreactivity was clearly observed in those cell bodies that were mainly distributed in the medulla and scattered in the granular layer (Fig. $2 A, B, D, E$, red labeling for $\mathrm{ABC} 2$ ). In the medulla, the ABC2-immunolabeled cells showed oval-shaped and rare dendrite morphological characteristics (Fig. 2E, red labeling, $G$, green labeling for $\mathrm{ABC} 2$ ) and can therefore be considered to be oligodendrocytes. Further evidence to this effect was obtained in two subsequent double-immunofluorescence staining experiments (Fig. 2A-I). All ABC2-immunolabeled cell bodies in both the medulla and the granular cell layer (Fig. 2B,E, red labeling for $A B C 2$ ) were found to be co-immunostained in the same tissue sections with an antibody against CNP, a marker protein that exists both in oligodendrocytes and in the myelin sheath (Fig. $2 C, F$, green labeling for CNP).

To confirm that $\mathrm{ABC} 2$ immunoreactivity was not localized in other kinds of glial cells, we chose an antibody against CD11b, a marker for microglial cells in brain sections, for double immunostaining with $\mathrm{ABC} 2$. This time, ABC2 immunoreactivity was labeled with green fluorescence and found to be restricted to oval-shaped cell bodies (Fig. 2G). The red-labeled CD11b immunoreactivity, on the other hand, was localized in another kind of cell, identified as the microglia cell type (Fig. 2I), and there was no observable overlap between the nuclei of these two immunolabeled cell types (Fig. $2 H$ ).

Further confirming staining was showed in the anterior commissure (Fig. 2J-L). The intense ABC2-immunoreactived cell bodies were clearly observed in the white matter region (Fig. $2 \mathrm{~J}$, red labeling), and this region from a neighboring section stained with MBP antibody showed intense positive labeling for myelin basic protein in whole white matter (Fig. $2 \mathrm{~K}$, red labeling). However, with an antibody for GFAP, the marker for astrocytes, most positive labeling was observed in the gray matter at the anterior commissure, and rare positive immunoreactivity was detected in the white matter (Fig. 2L, red labeling).

\section{Distribution of $\mathrm{ABC2}$ in various brain regions}

In addition to its distribution in the cerebellum as well as the anterior commissure, the distribution of $\mathrm{ABC} 2$ immunoreactivity in both the gray and white matter of other brain regions was also 
Figure 2. Identification of the $\mathrm{ABC} 2-$ immunolabeled cell type in the brain section. $A-F, \mathrm{ABC} 2$ immunoreactivity is restricted to cell bodies that have been identified by CNP marker as being oligodendrocytes. $A-C$, Low-magnification micrographs indicate that the immunoreactivities of both $\mathrm{ABC} 2$ (red) and CNP ( green) are localized mainly in the medulla and apparently rarely in the granular cell layer. $D-F$, Zoom-in micrographs from $A$ to $C$, respectively, show the precise colocalization of ABC2-immunolabeled cells with CNP; the arrows indicate the same location of the immunolabeled cells under different fluorescence microscopes. $A, D$, The red fluorescence (Alexa 546) represents $\mathrm{ABC} 2$ immunoreactivity and the blue (Hoechst 33258) indicates all nuclei, including a large number of nonimmunolabeled cells. $B, E$, Only $\mathrm{ABC} 2$ immunoreactivity is visible in the positive cell bodies. $C, F$, The green fluorescence labeling (Alexa 488) that represents the marker protein of CNP exists in both the oligodendrocytes and the myelin sheath. It is of note that all red $\mathrm{ABC} 2$ labeling surrounding the nuclei overlapped with green CNP labeling. $\mathrm{MoCb}$, Molecular layer; $G L$, granular layer; $M$, medulla of the cerebellum. $G-I, \mathrm{ABC} 2-$ immunoreactivity does not colocalize with marker labeling of CD11b for microglial cells. $G$, For comparison with $I$, $\mathrm{ABC} 2$ is labeled using green fluorescence (Alexa 488) is labeled for ABC2, and the oval-shaped positive cells (arrows) are observed. $H$, All cell nuclei are stained blue by Hoechst 33258; the arrows (the same as those used in $G$ ) showing the nuclei locations of $\mathrm{ABC} 2-$ immunolabeled cells in the medulla of the cerebellum and the arrowheads showing the nuclei of CD11b-immunolabeled cells (in $I$ ) indicate that there was no overlap with these two kinds of immunolabeling. I, The microglial cell bodies, which are immunolabeled with a marker antibody against CD11b (Alexa

546 , red $)$, are morphologically distinct from ABC2-immunolabeled cells $(G)$ in the same tissue sections of the cerebellum. $J-L, A B C 2$-immunoreactivity in the anterior commissure $(a c)$ compared with MBP and GFAP immunoreactivities. All positive immunoreactivities by above antibodies in the neighboring brain sections are labeled using red fluorescence (Alexa 546) and counterstained with Hoechst 33258. J, Most of the ABC2-immunolabeled cell bodies are distributed in the white matter region. $K$, The MBP immunoreactivity is observed intensely in the white matter, especially in the myelin sheaths and the oligodendrocytes, but the cell bodies are difficult to distinguish. $L$, The distribution of the GFAP immunolabeling, which specifically for astrocytes clearly shows a different localization pattern from oligodendrocytes immunolabeled by ABC2 or MBP antibodies. Scale bars, $50 \mu \mathrm{m}$.

investigated in this study by double-immunofluorescence labeling with CNP (Fig. 3). In the gray matter of the olfactory bulb (Fig. $3 A, O B$ ), cerebral cortex (Fig. $3 B, J, C X$ ), dentate gyrus (Fig. $3 C$, $D G$ ), corpora quadrigemina (Fig. $3 L, C Q$ ), thalamus, and hypothalamus, as well as in other parts, the double-immunolabeled (for ABC2 and CNP; overlapped as the yellow labeling) cells were found to be scattered within neurons and other kinds of glial cells.

In white matter throughout the entire brain, $\mathrm{ABC} 2$ immunostained cells were found to be in the majority. Intense double-immunolabeled cells were observed especially in the corpus callosum (Fig. $3 D, E, J, c c$ ), from the forceps minor part (Fig. $3 D, f m i$ ) to the forceps major part, the cingulum (Fig. $3 J, c g$ ), the ventral (Fig. 3E, vhc) and dorsal (Fig. $3 F$, dhc) hippocampal commissure, the anterior commissure (Fig. $3 H, a c$ ), the stria medullarias thalamus (Fig. $3 K, s m$ ), the optic chiasm (Fig. 3I, ox), the olfactory tubercle (Fig. $3 G, T u$ ), the olfactory tract, and the fibers pons, as well as in other regions.

\section{Ultrastructural localization of ABC2 in oligodendrocytes}

The white matter of brain tissues was cut ultrathin for the purposes of electron microscopy. In the medulla of the cerebellum, most of silver-gold particles that intensified the peroxidase-DAB reaction product for $\mathrm{ABC} 2$ immunoreactivity were found to be mostly distributed around the lysosomes of the oligodendrocytes (Fig. 4A). Using high magnification, the dense silver-gold particles, which were morphologically characterized as lysosomes (Fig. $4 B$ ), were clearly observed in the organellar membrane. The dense particles were also observed particularly in the trans face of the Golgi apparatus, and no specific particles were observed in all 

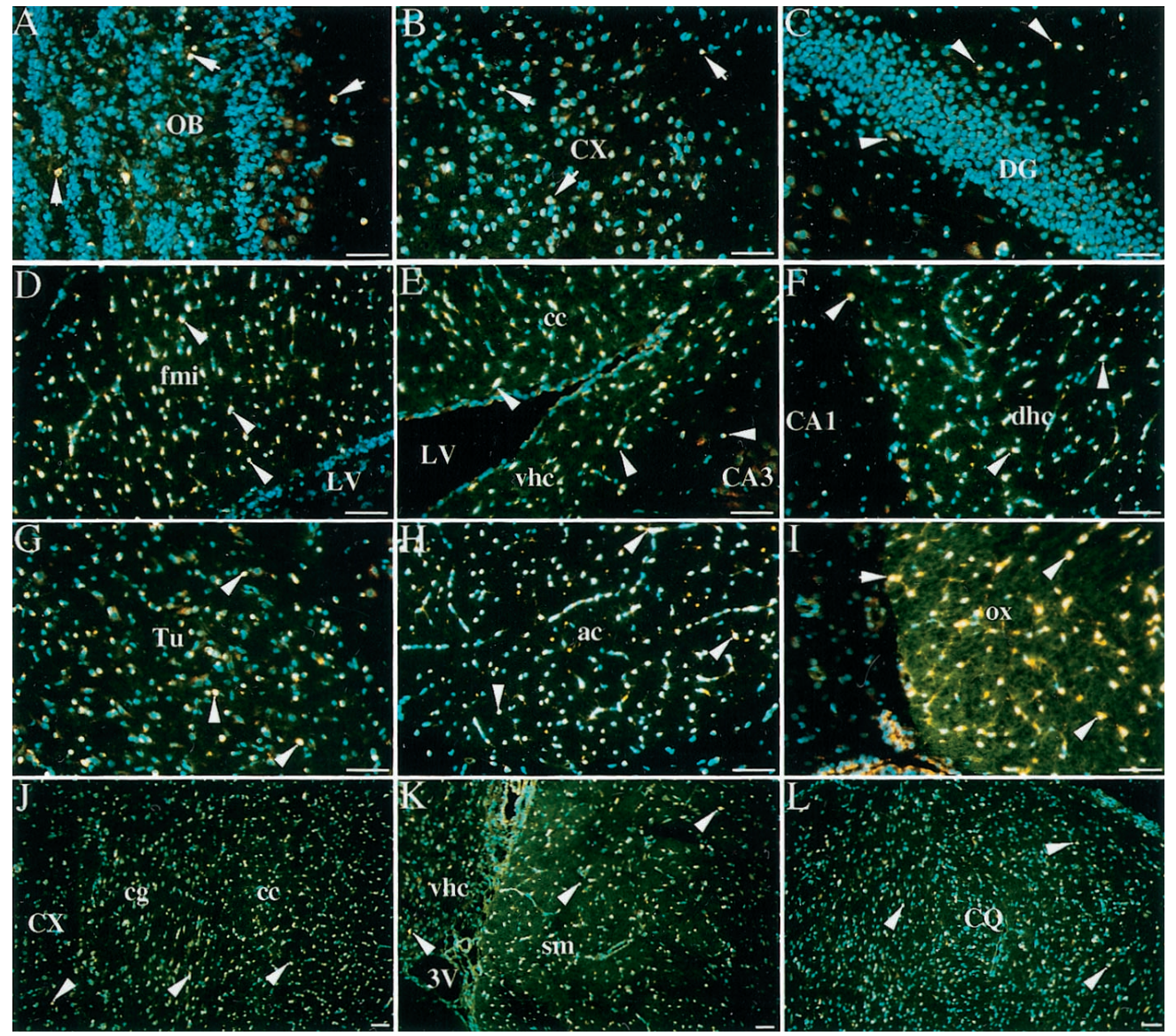

mitochondria and most endoplasmic reticulum or nucleus (Fig. $4 B$ ). At least 20 oligodendrocytes in cerebellum or other brain regions were examined. No specific $\mathrm{ABC} 2$ immunoreactivity was detected in the myelin sheath or the axon around the oligodendrocytes (Fig. 4A).

\section{Comparison of the histochemical distribution of $\mathrm{ABC2}$ mRNA and protein}

The x-ray film autoradiograms obtained from brain sections using an isotope-labeled riboprobe for $\mathrm{ABC} 2 \mathrm{mRNA}$ has been described in our previous work (Zhao et al., 2000). Both dark- and bright-field micrographs were made, and results are partly shown in Figure 5. Brain regions showing intense labeling for $\mathrm{ABC} 2$ mRNA coincided well with those demonstrating ABC2 immunoreactivity (described in this paper); however, a detailed description has been omitted here.

\section{Colocalization of ABC2 and LAMP1 or LAMP2 in the neuro-2a cell line}

It has been reported that mouse $\mathrm{ABC} 2$ mRNA was detected in the neuro-2a (N2a), a mouse neuroblastoma cell line, by Northern blot (Luciani et al., 1994). We used this cell line to confirm the lysosomal localization of $\mathrm{ABC} 2$ by double immunostaining with LAMP1 and LAMP2. As shown in Figure 6, most ABC2immunolabeled orgenelles (Fig. 6 A, green, $D$, red) were found to colocalize with lysosomal markers, either LAMP1 (Fig. 6B, red) or LAMP2 (Fig. 6E, green), and they were overlapped with each other by use of the confocal microscope (Fig. 6C,F, yellow).

\section{DISCUSSION}

This study has demonstrated that $\mathrm{ABC} 2$ is a novel lysosomeassociated membrane protein and is localized specifically in oli-
Figure 3. Distribution of ABC2 immunoreactivity, co-immunolabeled with $\mathrm{CNP}$, in the gray matter and white matter from different brain sections. The yellow positive labeling (some cells are indicated by arrowheads), which indicates colocalization of double fluorescence of Alexa 546 (red, for $\mathrm{ABC} 2$ ) and Alexa 488 (green, for CNP) in the same cells, was observed through a triple fluorescence filter cube. All cell nuclei in each brain section were labeled blue by Hoechst 33258. It is clear that the double-immunolabeled cells are rarely found in the gray matter $(A-C)$ but occur much more frequently in the olfactory tubercle $(G)$ and corpora quadrigemina $(L)$ and are distributed mainly in the white matter $(D-F, H-K) .3 V$, Third ventricle; $a c$, anterior commissure; $C A 1, C A 3$, the CA1 or CA3 field of the hippocampus; $c c$, corpus callosum; $c g$, cingulum; $C Q$, corpora quadrigemina; $C X$, cerebral cortex; $D G$, dentate gyrus of the hippocampal formation; $d h c$, dorsal hippocampal commissure; fmi, forceps minor corpus callosum; $L V$, lateral ventricle; $O B$, olfactory bulb; $o x$, optic chiasm; sm, stria medullaris thalamus; $T u$, olfactory tubercle; $v h c$, ventral hippocampal commissure. Scale bars, $50 \mu \mathrm{m}$. godendrocytes in the rat brain. A number of ABC transporter proteins are specific to a particular tissue or organelle and function specifically by coupling the hydrolysis of ATP to the transmembrane flux of molecules such as ions, sugars or polysaccharides, steroids, phospholipids, amino acids or peptides, and proteins, as well as of chemotherapeutic drugs. However, to date, only a couple of these transporters have been detected and investigated at length in the CNS. For example, sulfonylurea receptors, the regulator subunits of ATP-sensitive potassium channels (Inagaki et al., 1995, 1996), have been shown to be widely expressed in the rodent brain (Karschin et al., 1997). The present study has provided the first identification of a mammalian $\mathrm{ABC}$ membrane protein that is localized in oligodendrocytes in the mammalian brain and associated with lysosomes. Our findings should lead to the discovery of currently unknown aspects of both lysosomal membrane transport processes in oligodendrocytes and the physiological functions performed by $\mathrm{ABC} 2$ in the mammalian CNS.

\section{Specificity of the primary antibody for ABC2}

A polyclonal antibody was generated in a rabbit against the C-terminal domain of rat $\mathrm{ABC} 2$, which showed low homology with other peptides from the sequence databases on line. The antibody was affinity-purified to investigate the distribution of $\mathrm{ABC} 2$ protein in the rat brain. The specificity of the antibody was assessed by Western blot analysis. The present study revealed two bands of 260 and $250 \mathrm{kDa}$ from the COS- 1 cells transfected with rat $\mathrm{ABC} 2$ expression vector ( $\mathrm{pCMVrABC2}$ ), whereas no any band was revealed from those transfected with $\mathrm{pCMV}$ vector alone. This is consistent with our previous report that both 260 and $250 \mathrm{kDa}$ proteins also were detected by anti-HA antibody in 

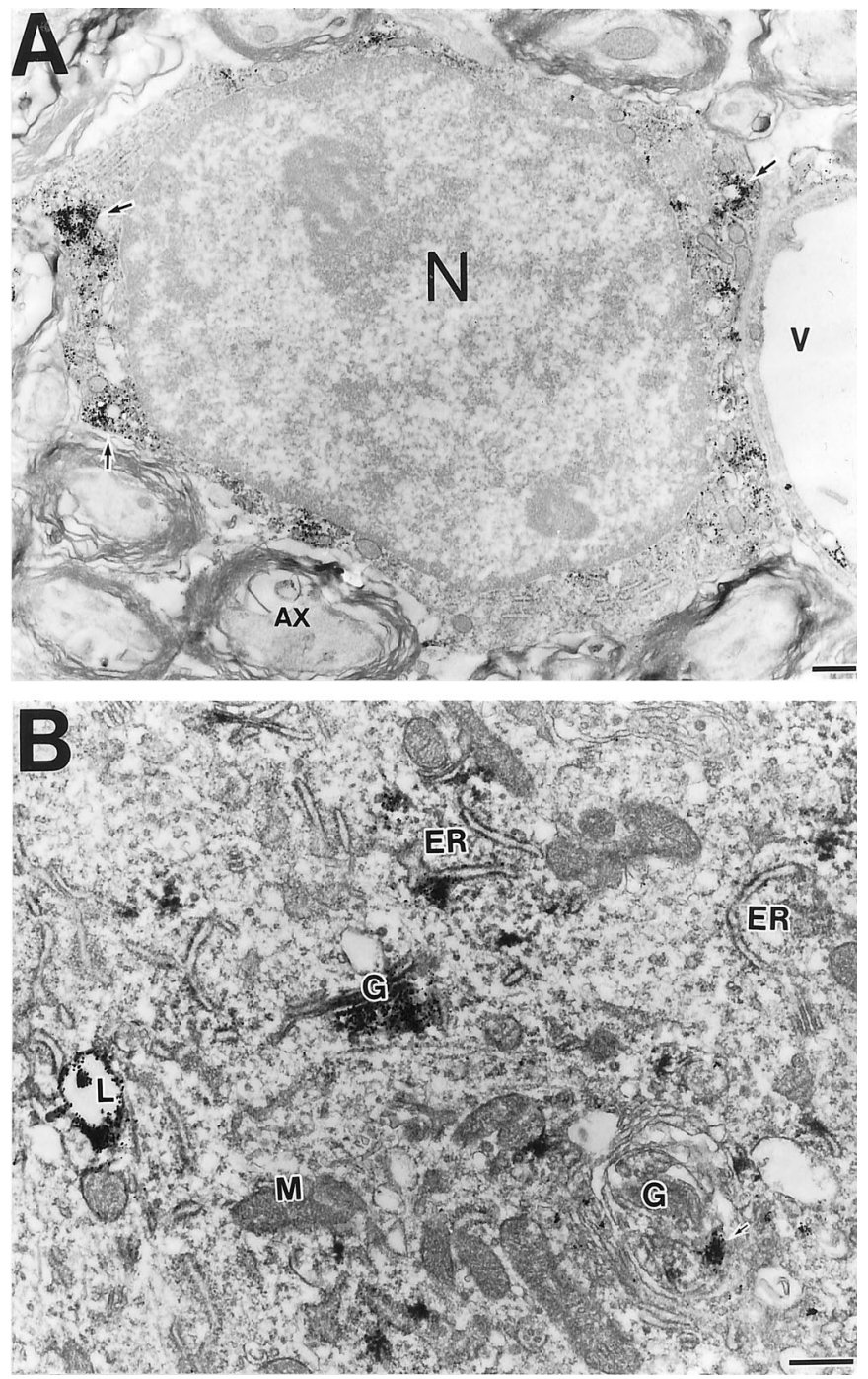

Figure 4. $\mathrm{ABC} 2$ in oligodendrocytes by immunoelectron microscopy. The ultrathin section was cut from the medulla of the cerebellum. The peroxidase-DAB reaction product from $\mathrm{ABC} 2$ immunohistochemistry was intensified with the silver-gold particles. $A$, Most of the intense labeling was observed around lysosomes (arrows), but only particular labeling or none at all was observed in other organelles at a magnification of $7000 \times$. Note that there is no specific labeling in the myelin sheath or the axon around the cell body. $A X$, Axon; $N$, nucleus; $V$, blood vessel. $B$, High-magnification $(10,000 \times)$ graphs for organellar localization of the $\mathrm{ABC} 2$ in oligodendrocytes. The silver-gold particles representing $\mathrm{ABC} 2$ immunoreactivities localized densely in lysosome membranes and particularly in the trans face of the Golgi apparatus (arrow). ER, Endoplasmic reticulum; $G$, Golgi body; $L$, lysosome; $M$, mitochondria. Scale bar, $500 \mathrm{~nm}$.

COS-1 cells transfected with an expression vector carrying ABC2-HA, in which a hemagglutinin epitope (YPYDVPDYA) was introduced into the $\mathrm{C}$ terminus of the $\mathrm{ABC} 2$ protein ( $\mathrm{Z}$ hao et al., 2000). Furthermore, the present study revealed a single band from rat brain between 260 and $250 \mathrm{kDa}$. The small difference of the mobilities between ABC2 protein expressed in COS-1 cells and in the brain might be attributable to the difference of glycosylation, because ABC2 is a glycoprotein (Zhao et al., 2000).

\section{Colocalization of $\mathrm{ABC} 2$ and $\mathrm{CNP}$ in the brain}

We have demonstrated that all ABC2-immunolabeled cell bodies in this study were also colocalized with CNP immunoreactivity. $\mathrm{CNP}$ is the main component of the Wolfgram protein fraction
(Drummond and Dean, 1980; Sprinkle et al., 1980) and has been widely used as a marker for myelin oligodendrocytes in the CNS. $\mathrm{CNP}$ is present in the cytoplasm-containing compartments of the oligodendrocytes and myelin sheaths but not in lamellae or cellular membranes (Braun et al., 1988). In contrast, we found that ABC2 immunoreactivity occurred only in cell bodies and was specifically localized to oligodendrocyte organelles. We observed that the ABC2-immunostained cells were mainly distributed within the white matter of the brain, in the interfascicular oligodendroglia that produce multilamellar myelin sheaths around nerve axons. In addition, many immunostained oligodendrocytes were observed in the gray matter, within neurons as so-called satellite cells, or adjacent to blood vessels. However, the functions of these latter cells remain unclear. The distribution pattern of immunostained oligodendrocytes coincided well with those of CNP immunohistochemistry (Braun et al., 1988).

\section{$A B C 2$ as a specific marker for oligodendrocytes but not for myelin sheaths}

Numerous tissue-specific chemical components have been isolated and identified from myelin oligodendrocytes (as well as from Schwann cells) and may have been used as specific markers for cell identification. To date, $>40$ enzymes, including CNP, ceramide galactosyltransferase, glutathione $S$-transferase, and carbonic anhydrase, are actively expressed at specific stages during myelinization (Newman et al., 1995; Wiesinger, 1995). However, CNP is widely used as the marker in experiments involving the adult CNS, as was the case in this study. Other proteins found in the myelin sheath are galactocerebroside, a kind of typical myelin lipid also used as a specific marker in cultured cells (Benjamins et al., 1987), sulfatide, cholesterol, ethanolamine phosphatide, lecithin, and plasmalogen (Morell et al., 1994). Furthermore, $60-80 \%$ of the protein mass in the myelin sheath is made up of proteolipid protein and MBP. Other glycoproteins, such as myelin-associated glycoprotein, myelin-oligodendrocyte glycoprotein (MOG), and oligodendrocyte-myelin glycoprotein, have also been isolated (Newman et al., 1995). Although these components exist both in the myelin-sheath and in oligodendrocytes, a number of them, such as CNP, MBP, and MOG, are localized in different regions at the ultrastructural level (Brunner et al., 1989). In the present study, we compared not only the immunocolocalizaiton of $\mathrm{ABC} 2$ with $\mathrm{CNP}$ but also its colocalization with $\mathrm{MBP}$, and obtained a similar result. We therefore propose that, although further investigation is needed into the expression of $\mathrm{ABC} 2$ in the peripheral nervous system and during development, ABC2 can be used as a specific marker for oligodendrocytes. We also have compared ABC2 with markers for other glial cells such as CD11b, in the case of microglial cells, and GFAP, in the case of astrocytes (Debus et al., 1983), and they shown no cross-immunostaining with each other.

\section{ABC2 as a lysosomal membrane protein}

The colocalization of ABC2 with lysosome-associated membrane proteins (LAMP1 and LAMP2) and the immunoelectron microscopy as well as crude membrane-immunoblotting results in the present study have clearly shown ABC2 to be a novel lysosomeassociated membrane protein. Lysosomes are membrane-bound organelles with an acidic internal milieu containing hydrolytic enzymes for degrading for various substances. The major structural components of lysosomal membrane are glycoproteins with molecular weights between 90 and $110 \mathrm{kDa}$ (Peters and von Figura, 1994). 

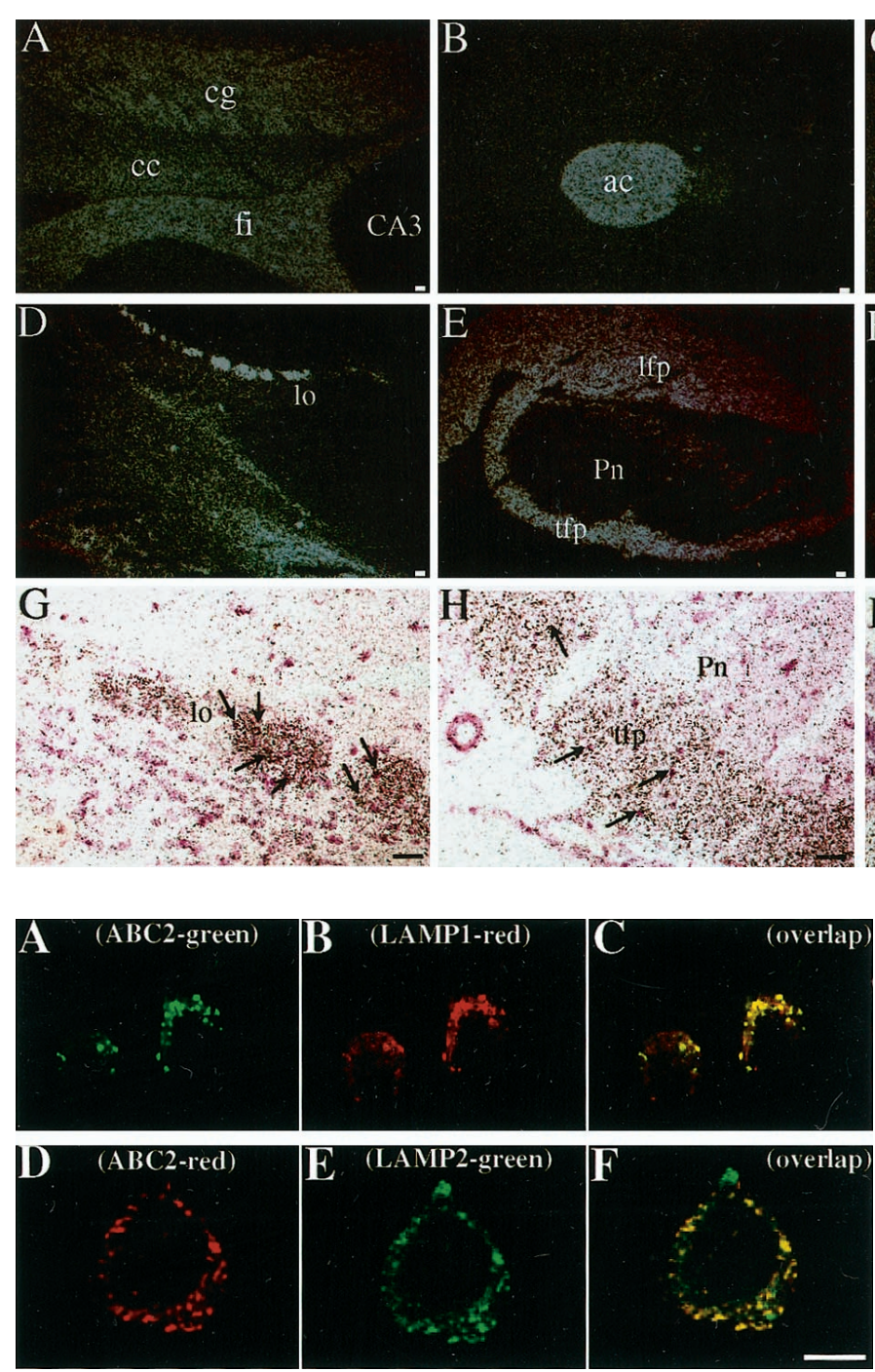

Figure 6. Colocalization of $\mathrm{ABC} 2$ and lysosomal markers LAMP1 or LAMP2 with confocal microscopy in neuro-2a cells, an ABC2-expressing mouse neuroblastoma cell line. The green labeling for $\mathrm{ABC} 2-$ immunoreactivity $(A)$ and the red labeling for LAMP1 immunoreactivity $(B)$ are mostly overlapped as yellow in the lysosomes $(C)$. In contrast, the red labeling for $\mathrm{ABC} 2$ immunoreactivity $(D)$ and the green labeling for LAMP2 immunoreactivity $(E)$ are also overlapped well as yellow in lysosomes of the neuro-2a cells $(F)$. Scale bars, $20 \mu \mathrm{m}$.

The lysosomal membrane regulates the transport activities of substances such as proteins, lipids, nucleic acids, and saccharides of the cellular components as well as toxins, drugs, and heavy metals from the cytoplasm into the lysosome, as well as the release of digested molecules from the lysosomal lumen into the cytoplasm. These processes usually consume energy. Therefore, $\mathrm{ABC}$ transporter proteins were potential candidates to be performing some of these transporter activities. In this study, we have identified $\mathrm{ABC} 2$ as being specifically localized in the lysosome membranes of oligodendrocytes. Although the ABC protein HMT1, involved in heavy-metal tolerance (Ortiz et al., 1992), and the yeast cadmium factor protein, a glutathione $S$-conjugate pump (Li et al., 1996), have been found in the yeast vacuolar membrane (equivalent to the lysosomal compartment), until this study no ABC transporter had as yet been identified as

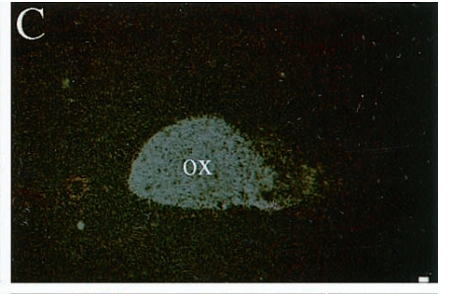

Figure 5. Dark- and bright-field micrographs of the distribution of $\mathrm{ABC} 2$ mRNA in brain tissues. Sections, after hybridization with $\left.{ }^{35} \mathrm{~S}\right]$-labeled riboprobe for $\mathrm{ABC} 2$, were dipped in a nuclear track emulsion and exposed for 1 week. Intense labeling was observed in the white matter and weak labeling in the gray matter throughout the whole brain. The areas around the corpus callosum $(A$, coronal section), anterior commissure ( $B$, sagittal), optic chiasm ( $C$, sagittal), olfactory bulb $(D$, sagittal), pontine nuclei $(E$, sagittal), and the lobe of cerebellum ( $F$, sagittal) showed up in the dark-field. The bright-field micrographs $(G-I)$ are magnified from the relative regions $(E, F)$, and the dense silver particles representing ABC2 mRNA are observed over many cell bodies within the white matter ( $a r$ rows). ac, Anterior commissure; $C A 3$, the CA3 field of hippocampus; $c c$, corpus callosum; cg, cingulum; $f i$, fimbria hippocampus; $G L$, granular layer of cerebellum; lfp, longitudinal fasciculus pons; $l o$, lateral olfactory tract; $M$, medulla of cerebellum; $\mathrm{MoCb}$, molecular layer of cerebellum; $o x$, optic chiasm; $P n$, pontine nuclei; $t f p$, transverse fibers pons. Scale bars, $50 \mu \mathrm{m}$. a mammalian lysosomal membrane protein. It should be noted that almost at the same time as the completion of this manuscript, one paper did describe a half-molecule ABC transporter, ABCB9, which was mainly expressed in rodent testes and was localized in the lysosomes in transfected cells (Zhang et al., 2000). Although data are needed that directly demonstrate the intracellular localization of ABCB9 (this half-transporter belongs to a different subfamily than the full-length $\mathrm{ABC} 2$ transporter) in testis, this in vitro data supports our present in vivo findings. Further studies should be performed to investigate whether $\mathrm{ABC} 2$ also plays the lysosome-specific role in the testis (we have detected $\mathrm{ABC} 2$ in testis but further studies are needed), whether ABCB9 plays a role in both testis and brain, or whether either protein plays a role in other tissues. Several other organellespecific ABC proteins, however, have been reported: four murine peroxisomal ABC half-transporters (Berger et al., 1999), the ALD protein (ALDP) (Mosser et al., 1993), ADL-related protein (ALDRP) (Holzinger et al., 1997a), $70 \mathrm{kDa}$ peroxisomal membrane protein (PMP70), and PMP70-related protein (P70R or PMP69) (Holzinger et al., 1997b); the mitochondrial ABC protein (M-ABC1) (Hogue et al., 1999) and ABC7 (Csere et al., 1998); and the Tap1 and Tap2 as a heterodimer associated with ABC transporters in the endoplasmic reticulum (Gileadi and Higgins, 1997).

\section{Significance of $A B C 2$ expressed in the brain}

In the $\mathrm{ABC} 1$ subfamily, $\mathrm{ABC} 1$ and $\mathrm{ABCR}$ have been proposed to be flippases for intracellular cholesterol and protonated $N$-retinylidene-phosphatydylethanolamine, respectively (Weng et al., 1999). The N-terminal 40-amino acid sequences including the first hydrophobic segment, the membrane-spanning domains, and the nucleotide-binding domains of the four identified members of this subfamily (ABC1, ABC2, ABC3, and ABCR) between murine and human are strongly conserved (Zhao et al., 2000); however, the fundamental function of $\mathrm{ABC} 2$ remains unknown. The ABC2 gene is located at chromosome 9q34 (Luciani et al., 
1994), which is a homogeneous staining region for an estramustine-resistant human ovarian carcinoma cell line. One research group has in fact used this cell line to show that amplification and overexpression of $\mathrm{ABC} 2$ contributes to estramustine resistance (Laing et al., 1998). The current findings that ABC2 is expressed in oligodendrocytes and associated with lysosomes provides evidence that this transporter should be studied further in the CNS. Investigation of cultured oligodendrocytes may potentially reveal an essential cellular role for $\mathrm{ABC}$ transporters. Oligodendrocytes are well known as the myelinating glial cells, and hypomyelination or demyelination diseases such as genetic leukodystrophy, multiple sclerosis, and multisystem atrophy are all closely linked to the intracellular metabolism connected with oligodendrocyte lysosomes. This strongly suggests that $\mathrm{ABC} 2$, as a lysosomal membrane transporter of oligodendrocytes, may be involved in normal myelination and therefore may be associated in some way with these degeneration processes. As with the other members of $\mathrm{ABC} 1$ subfamily, $\mathrm{ABC} 1$ and $\mathrm{ABCR}$ have been identified as the causal genes for certain genetic diseases. Further investigation of $\mathrm{ABC} 2$ will provide more insight into its functional significance.

\section{REFERENCES}

Allikmets R, Gerrard B, Hutchinson A, Dean M (1996) Characterization of the human $\mathrm{ABC}$ superfamily: isolation and mapping of 21 new genes using the expressed sequence tags database. Hum Mol Genet 5:1649-1655.

Allikmets R, Singh N, Sun H, Shroyer NF, Hutchinson A, Chidambaram A, Gerrard B, Baird L, Stauffer D, Peiffer A, Rattner A, Smallwood P, Li Y, Anderson KL, Lewis RA, Nathans J, Leppert M, Dean M Lupski JR (1997) A photoreceptor cell-specific ATP-binding transporter gene (ABCR) is mutated in recessive Stargardt macular dystrophy. Nat Genet 15:236-246.

Benjamins JA, Callahan RE, Montgomery IN, Studzinski DM, Dyer CA (1987) Production and characterization of high titer antibodies to galactocerebroside. J Neuroimmunol 14:325-338.

Berger J, Albet S, Bentejac M, Netik A, Holzinger A, Roscher AA, Bugaut M, Forss-Petter S (1999) The four murine peroxisomal ABCtransporter genes differ in constitutive, inducible and developmental expression. Eur J Biochem 265:719-727.

Bodzioch M, Orso E, Klucken J, Langmann T, Bottcher A, Diederich W, Drobnik W, Barlage S, Buchler C, Porsch-Ozcurumez M, Kaminski WE, Hahmann HW, Oette K, Rothe G, Aslanidis C, Lackner KJ, Schmitz G (1999) The gene encoding ATP-binding cassette transporter 1 is mutated in Tangier disease. Nat Genet 22:347-351.

Braun PE, Sandillon F, Edwards A, Matthieu JM, Privat A (1988) Immunocytochemical localization by electron microscopy of $2^{\prime}, 3^{\prime}$-cyclic nucleotide $3^{\prime}$-phosphodiesterase in developing oligodendrocytes of normal and mutant brain. J Neurosci 8:3057-3066.

Brooks-Wilson A, Marcil M, Clee SM, Zhang LH, Roomp K, van Dam M, Yu L, Brewer C, Collins JA, Molhuizen HO, Loubser O, Ouelette BF, Fichter K, Ashbourne-Excoffon KJ, Sensen CW, Scherer S, Mott S, Denis M, Martindale D, Fronhlich J, Morgan K, Koop B, Pimstone S, Kastelein JJ, Genest Jr J, Hayden MR (1999) Mutations in ABC1 in Tangier disease and familial high-density lipoprotein deficiency. Nat Genet 22:336-345.

Brunner C, Lassmann H, Waehneldt TV, Matthieu JM, Linington C (1989) Differential ultrastructural localization of myelin basic protein, myelin/oligodendroglial glycoprotein, and 2 ', 3'-cyclic nucleotide $3^{\prime}$ phosphodiesterase in the CNS of adult rats. J Neurochem 52:296-304.

Csere P, Lill R, Kispal G (1998) Identification of a human mitochondrial ABC transporter, the functional orthologue of yeast Atm1p. FEBS Lett 441:266-270.

Dean M, Allikmets R (1995) Evolution of ATP-binding cassette transporter genes. Curr Opin Genet Dev 5:779-785.

Debus E, Weber K, Osborn M (1983) Monoclonal antibodies specific for glial fibrillary acidic (GFA) protein and for each of the neurofilament triplet polypeptides. Differentiation 25:193-203.

Decottignies A, Goffeau A (1997) Complete inventory of yeast ABC proteins. Nat Genet 15:137-145.

Doige CA, Ames GFL (1993) ATP-dependent transport systems in bacteria and humans: relevance to cystic fibrosis and multidrug resistance. Annu Rev Microbiol 47:291-319.

Drummond RJ, Dean G (1980) Comparison of $2^{\prime}, 3^{\prime}$-cyclic nucleotide $3^{\prime}$-phosphodiesterase and the major component of Wolfgram protein W1. J Neurochem 35:1155-1165.
Dubois-Dalcq M, Feigenbaum V, Aubourg P (1999) The neurobiology of X-linked adrenoleukodystrophy, a demyelinating peroxisomal disorder. Trends Neurosci 22:4-12.

Gallyas F, Gorcs T, Merchenthaler I (1982) High-grade intensification of the end-product of the diaminobenzidine reaction for peroxidase histochemistry. J Histochem Cytochem 30:183-184.

Gileadi U, Higgins CF (1997) Membrane topology of the ATP-binding cassette transporter associated with antigen presentation (Tap1) expressed in Escherichia coli. J Biol Chem 272:11103-11108.

Guan JL, Wang QP, Shioda S (2000) Observation of the ultrastructure and synaptic relationaships of angiotensin II-like immunoreactive neurons in the rat area postrema. Synapse 38:231-237.

Higgins CF (1992) ABC transporters: from microorganisms to man. Annu Rev Cell Biol 8:67-113.

Higgins CF (1994) Flip-flop: the transmembrane translocation of lipids. Cell 79:393-395.

Hogue DL, Liu L, Ling V (1999) Identification and characterization of a mammalian mitochondrial ATP-binding cassette membrane protein. $\mathbf{J}$ Mol Biol 285:379-389.

Holzinger A, Kammerer S, Berger J, Roscher AA (1997a) cDNA cloning and mRNA expression of the human adrenoleukodystrophy related protein (ALDRP), a peroxisomal ABC transporter. Biochem Biophys Res Commun 239:261-264.

Holzinger A, Kammerer S, Roscher AA (1997b) Primary structure of human PMP69, a putative peroxisomal ABC-transporter. Biochem Biophys Res Commun 237:152-157.

Hyde SC, Emsley P, Hartshorn MJ, Mimmack MM, Gileadi U, Pearce SR, Gallagher MP, Gill DR, Hubbard RE, Higgins CF (1990) Structural model of ATP-binding proteins associated with cystic fibrosis, multidrug resistance and bacterial transport. Nature 346:362-365.

Illing M, Molday LL, Molday RS (1997) The 220-kDa rim protein of retinal rod outer segments is a member of the $\mathrm{ABC}$ transporter superfamily. J Biol Chem 272:10303-10310.

Inagaki N, Gonoi T, Clement JP, Wang CZ, Aguilar-Bryan L, Bryan J, Seino S (1996) A family of sulfonylurea receptors determines the pharmacological properties of ATP-sensitive K channels. Neuron 16:1011-1017.

Inagaki N, Gonoi T, Clement JP4, Namba N, Inazawa J, Gonzalez G, Aguilar-Bryan L, Seino S Bryan J (1995) Reconstitution of IKATP: an inward rectifier subunit plus the sulfonylurea receptor. Science 270:1166-1170.

Kamijo K, Taketani S, Yokota S, Osumi T, Hashimoto T (1990) The $70-\mathrm{kDa}$ peroxisomal membrane protein is a member of the $\mathrm{Mdr}(\mathrm{P}-$ glycoprotein)-related ATP-binding protein superfamily. J Biol Chem 265:4534-4540.

Karlsson K, Carlsson SR (1998) Sorting of lysosomal membrane glycoproteins lamp-1 and lamp-2 into vesicles distinct from mannose 6-phosphate receptor/gamma-adaptin vesicles at the trans-Golgi network. J Biol Chem 273:18966-18973.

Karschin C, Ecke C, Ashcroft FM, Karschin A (1997) Overlapping distribution of K (ATP) channel-forming Kir6.2 subunit and the sulfonylurea receptor SUR1 in rodent brain. FEBS Lett 401:59-64.

Klugbauer N, Hofmann F (1996) Primary structure of a novel ABC transporter with a chromosomal localization on the band encoding the multidrug resistance-associated protein. FEBS Lett 391:61-65.

Laing NM, Belinsky MG, Kruh GD, Bell DW, Boyd JT, Barone L, Testa JR, Tew KD (1998) Amplification of the ATP-binding cassette 2 transporter gene is functionally linked with enhanced efflux of estramustine in ovarian carcinoma cells. Cancer Res 58:1332-1337.

Li ZS, Szczypka M, Lu YP, Thiele DJ, Rea PA (1996) The yeast cadmium factor protein (YCF1) is a vacuolar glutathione S-conjugate pump. J Biol Chem 271:6507-6517.

Linton KJ, Higgins CF (1998) The Escherichia coli ATP-binding cassette (ABC) proteins. Mol Microbiol 28:5-13.

Luciani MF, Denizot F, Savary S, Mattei MG, Chimini G (1994) Cloning of two novel $\mathrm{ABC}$ transporters mapping on human chromosome 9. Genomics 21:150-159.

Milligan CE, Conningham TJ, Levitt P (1991) Differential immunochemical markers reveal the normal distribution of brain macrophages and microglia in the developing rat brain. J Comp Neurol 314:125-135.

Morell P, Quarles RH, Norton WT (1994) Myelin formation, structure and biochemistry. In: Basic neurochemistry (Siegel W, Agronoff B, Albers RW, Molinoff P, eds), pp 117-143. New York: Raven.

Mosser J, Douar AM, Sarde CO, Kioschis P, Feil R, Moser H, Poustka AM, Mandel JL, Aubourg P (1993) Putative X-linked adrenoleukodystrophy gene shares unexpected homology with $A B C$ transporters. Nature 361:726-730.

Newman S, Saito M, Yu RK (1995) Biochemistry of myelin protein and enzymes. In: Neuroglia (Kettenmann H, Ransom BR, eds), pp 535-554. New York: Oxford UP.

Orso E, Broccardo C, Kaminski WE, Bottcher A, Liebisch G, Drobnik W, Gotz A, Chambenoit O, Diederich W, Langmann T, Spruss T, Luciani MF, Rothe G, Lackner KJ, Chimini G, Schmitz G (2000) Transport of lipids from Golgi to plasma membrane is defective in Tangier disease patients and $A b c 1$-deficient mice. Nat Genet 24:192-196. 
Ortiz DF, Kreppel L, Speiser DM, Scheel G, McDonald G, Ow DW (1992) Heavy metal tolerance in the fission yeast requires an ATPbinding cassette-type vacuolar membrane transporter. EMBO J 11:3491-3499.

Paulusma CC, Bosma PJ, Zaman GJ, Bakker CT, Otter M, Scheffer GL, Scheper RJ, Borst P, Oude Elferink RP (1996) Congenital jaundice in rats with a mutation in a multidrug resistance-associated protein gene. Science 271:1126-1128.

Peters A, Palay SL, Webster J (1976) The fine structure of the nervous system: the neurons and supporting cells. Philadelphia: W. B. Saunders.

Peters C, von Figura K (1994) Biogenesis of lysosomal membranes. FEBS Lett 346:108-114.

Ringpfeil F, Lebwohl MG, Christiano AM, Uitto J (2000) Pseudoxanthoma elasticum: mutations in the MRP6 gene encoding a transmembrane ATP-binding cassette (ABC) transporter. Proc Natl Acad Sci USA 97:6001-6006.

Rust S, Rosier M, Funke H, Real J, Amoura Z, Piette JC, Deleuze JF, Brewer HB, Duverger N, Denefle P, Assmann G (1999) Tangier disease is caused by mutations in the gene encoding ATP-binding cassette transporter 1. Nat Genet 22:352-355.

Saurin W, Hofnung M, Dassa E (1999) Getting in or out: early segregation between importers and exporters in the evolution of ATP-binding cassette (ABC) transporters. J Mol Evol 48:22-41.

Sheppard DN, Welsh MJ (1999) Structure and function of the CFTR chloride channel. Physiol Rev 79:S23-45.

Shioda S, Shuto Y, Somogyvari-Vigh A, Legradi G, Onda H, Coy DH, Nakajo S, Arimura A (1997) Localization and gene expression of the receptor for pituitary adenylate cyclase-activating polypeptide in the rat brain. Neurosci Res 28:345-354.

Sprinkle TJ, Agee JF, Tippins RB, Chamberlain CR, Faguet GB, De Vries GH (1987) Monoclonal antibody production to human and bovine 2',3'-cyclic nucleotide $3^{\prime}$-phosphodiestrase (CNPase): high- specificity recognition in whole brain acetone powders and conservation of sequence between CNP1 and CNP2. Brain Res 426:349-357.

Sprinkle TJ, Wells MR, Garver FA, Smith DB (1980) Studies on the Wolfgram high molecular weight CNS myelin proteins: relationship to $2^{\prime}, 3^{\prime}$-cyclic nucleotide $3^{\prime}$-phosphodiesterase. J Neurochem 35:1200-1208.

Strautnieks SS, Bull LN, Knisely AS, Kocoshis SA, Dahl N, Arnell H, Sokal E, Dahan K, Childs S, Ling V, Tanner MS, Kagalwalla AF, Nemeth A, Pawlowska J, Baker A, Mieli-Vergani G, Freimer NB, Gardiner RM, Thompson RJ (1998) A gene encoding a liver-specific ABC transporter is mutated in progressive familial intrahepatic cholestasis. Nat Genet 20:233-238.

Thomas PM, Cote GJ, Wohllk N, Haddad B, Mathew PM, Rabl W, Aguilar-Bryan L, Gagel RF, Bryan J (1995) Mutations in the sulfonylurea receptor gene in familial persistent hyperinsulinemic hypoglycemia of infancy. Science 268:426-429.

Weng J, Mata NL, Azarian SM, Tzekov RT, Birch DG, Travis GH (1999) Insights into the function of Rim protein in photoreceptors and etiology of Stargardt's disease from the phenotype in abcr knockout mice. Cell 98:13-23.

Wiesinger H (1995) Glia-specific enzyme systems. In: Neuroglia (Kettenmann H, Ransom BR, eds), pp 488-499. New York: Oxford UP.

Zhang F, Zhang W, Lin L, Fisher CL, Hui D, Childs S, Dorovini-Zis K, Ling V (2000) Characterization of ABCB9, an ATP-binding cassette protein associated with lysosomes. J Biol Chem 275:23287-23294.

Zhao LX, Zhou CJ, Tanaka A, Nakata M, Hirabayashi T, Amachi T, Shioda S, Ueda K, Inagaki N (2000) Cloning, characterization and tissue distribution of the rat ATP-binding cassette (ABC) transporter ABC2/ABCA2. Biochem J 350:865-872.

Zhou CJ, Shioda S, Shibanuma M, Nakajo S, Funahashi H, Nakai Y, Arimura A, Kikuyama S (1999) Pituitary adenylate cyclase-activating polypeptide receptors during development: expression in the rat embryo at primitive streak stage. Neuroscience 93:375-391. 